\title{
AN ECONOMIC INSIGHT INTO THE PRODUCTION OF SWEET SORGHUM AND ETHANOL IN WESTERN TAMIL NADU
}

\author{
C.Sekhar, S.R. Rajesh, K.Uma, N.Venkatesa Palanisamy and M.Santhan* \\ Directorate of CARDS, Tamil Nadu Agricultural University, Coimbatore, TN, India \\ * Bannari Amman Sugars ltd, Sathyamangalam, TN, India
}

\begin{abstract}
The study is an attempt to identify the economic feasibility of production of sweet sorghum and ethanol. The buy back mechanism is prevalent between Messrs Bannari Amman Sugars Limited and the farmers of Sathyamangalam Taluk. The study has identified the land use pattern in vogue with the farmers revealed that as the size of holding increases, the area allocated for sweet sorghum is also increases. The cost structure in respect of $A 1, B$ and $C$ involved in establishment of sweel sorghum are also discussed. Among various cost componenis, human labor, fertilizer's and manure consumed to a level of around 60 per cent. The cost of production of ethanol from sweet sorghum is little higher than the one drawn from molasses. As age of the sweet sorghum advances, the juice weight obtained from a ton of stalk is decreasing. Hence, optimum age of harvesting is very important. The optimum age of harvesting of sweet sorghum for higher volume of ethanol production and higher yield of stalk are also discussed.
\end{abstract}

Key words: sweet sorghum, ethanol, economic feasibility, optimum age for harvesting

\section{IN:RODUCTION}

Sweet sorghum (Sorghum bicolor (L.) Moench) is a $\mathrm{C}_{4}$ plant, ranging in height between 3 and $5 \mathrm{~m}$. It is known as a "high energy crop" because of its high photosynthetic rate, and also called as "the calırl among crops" due to its characteristics such as drought resistance, tolerance to water logging and saline-alkali resistance, as well as its wide adaptability.

Sweet sorghum is a versatile crop that can be used for silage making, alcohol production and as a grain crop. Loam and sandy loam soils generally allow better syrup production. Good soil drainage is important for good performance. High-quality syrup can be made from sweet sorghum grown on a wide range of soil types.

Sweet sorghum is commonly grown in rows spaced 36 to 42 inches apart. Spacing wider than 42 inches can result in yield reduction. Planting depths for the seed of sweet sorghum should be about 1 inch, with deeper coverage on light sandy soils and shallower coverage on heavy clay soils. High quality syrup is produced when the grain is harvested before the mature or ripe seed stage. Sucrose percentage and syrup 
yields generally increase as the stalk matures to the ripe seed stage. To obtain high-quality syrup and high yields, it should be harvested when the seed is in the soft dough stage.

\section{Swect sorghum in India}

The sugar industry in India is the second largest processing industry, next to cotton textiles. More than 350 factories have been established in India with an installed capacity of about 20 million tonnes of sugar and 60-80 million tonnes of molasses as a by product. Sugarcane is used as raw material for sweetening agents in India like sugar (30-33\%), gur (50-60\%) and khandsari (6-7\%). Molasses, a by-product from sugar industries is utilized for production of alcohol, acetic acid, citric acid etc.

As water availability in sugarcane cultivated areas has become a major constraint, sweet sorghum can be an effective alternative that could supplement sugarcane in ethanol production. Sweet sorghum is rich in stalk sucrose and sugars which resembles closely sugarcane for its juicy stalk. It provides grain and stem that can be used for the production of sugar, alcohol, syrup, jaggery, feed and fodder. However, its stalks have a greater potential to be used as a raw material for fuel grade ethanol production. (Dayakar Rao, et al, 2004 ). Sweet sorghum was introduced into India by NARI in late 1960s. As the American varieties produced very little grain of inferior quality, they were crossed at NARI with local grain types. This increased their adaptability to local geographic and climatic conditions. Due to economic considerations, emphasis was given to high grain and biomass as well as sugar yields in developing new sorghum varieties. Instead of pure lines, NARI opted for hybrid production in order to speedily combine high grain, biomass, and sugar production ability into one cultivar. The sweet-stem sorghum hybrid "Madhura" has been developed at NARI for ethanol, syrup and jaggery (unrefined sugar) production.

Ethanol is a renewable source of energy which can be produced from feed stocks such as molasses, com, sweet sorghum etc. The Government of India started an initiative to make it mandatory to add 5\% thanol to gasoline, resulting in increased demand for Madhura seed. About 70 per cent of Indian crude oil requirements are met through imports, which is draining our exchequer. Therefore, ethanol blending with petrol is expected to save foreign exchange worth of Rs 830 crores per ycar besides generating jobs, and controlling carbon dioxide emissions.

India consumes about 78 lakh kilolitres of petrol annually and the ethanol requirement for blending is estimated to be 3.9 lakh kilolitres, which provides an immense scope for the agricultural sector. But the existing level of ethanol production from sugarcane molasses is only 2.0 kilolitres. The installed capacity of Indian ethanol industry during 2001-02 was 3.2 billion litres per annum but it was under utilized (41 per cent) and produced to the tune of 1.3 billion litres. Thus the underutilized capacity can le best utilized by using alternate feedstocks such as sweet sorghum as supplementary raw material. 


\section{Tamil Nadu Scenario}

Pursuant to the decision of the Government of India to introduce Ethanol doped petrol for use as fuel in Tamil Nadu, the State Government have issued orders accepting in principle the manufacture of Anhydrous Alcohol (Ethanol) by the distilleries in the State.

In Tamil Nadu, 15 Distilleries are manufacturing alcohol. Among the 15 Distilleries, 13 are in the Private Sector and 2 are in the Co-operative Sector. Bannari Amman sugars Ltd is one of the leading distilleries, is being cultivated sweet sorghum by entering contractual arrangement with the farmers of Erode district as a pilot project. As water availability in many irrigated areas of Erode has become a major constraint, sweet sorghum can be effective alternative for sugarcane in ethanol production.

Keeping this in view, an attempt is made in the present study

1) to estimate the optimum age of harvesting, cost of production and returns of sweet sorghum;

2) To examine the economic feasibility of ethanol production from sweet sorghum; and

3) To suggest appropriate policy measures, for expansion of area under sweet sorghum in Tamil Nadu.

\section{METHODOLOGY}

Sweet sorghum is cultivated in Erode district and this district was chosen purposively. Among the taluks, Sathyamangalam taluk of Erode district was selected in the first stage as it had maximum number of farmers cultivating Sweet sorghum. In this taluk, the village wise list of sweet sorghum growers were obtained from the records of Bannari Amman Sugars Ltd, who are the promoters of the crop in the district. From the list, five villages were selected based on higher area in cultivation of sweet sorghum in the second stage. The ranking villages (Figure -1) were Varadhampalayam, Akkarainegamam, Thandampalayam, Alathukombai, and Uthandiyur. From the list 10 Sweet sorghum growing farmers were selected at random from each village in the third stage to cover 50 samples from five villages following three stage random sampling technique. Personal interview method was adopted using structured questionnaire designed for the purposc to collect the required data from 50 sample farmers.

To analyse the costs and returns, the concept adopted by Directorate of Economics and Statistics (DES), New Delhi was adopted viz., cost A, cost B, cost C. (DES, Government of India, 1970-71).

Cost A: Includes seeds, hired human labour, machine labour, inorganic fertilizers. Organic manures, insecticide, land revenue, depreciation on farm implements and machineries and interest on working capital.

Cost B: Includes cost A plus rental value of owned land and interest on fixcd capital.

Cost C: Includes cost B plus imputed value of family labour. 
To highlight the turnover for the investment on various resources, Output-Input Ratio was employed. Here, Output refers to the gross return obtained from main and by product of sweet sorghum and the Input here refers to the total cost which is described as Cost ' $\mathrm{C}$ '.

Besides this, the optimum age of harvesting is very important to produce quality syrup. For that purpose, the data generated from the experiments conducted by M/S Bannari Amman Sugars Limited was utilized. The tables generated for the study involves both primary and secondary data which are analyzed using percentage analysis for drawing inferences.

\section{Figure 1: Map Showing the Study area}

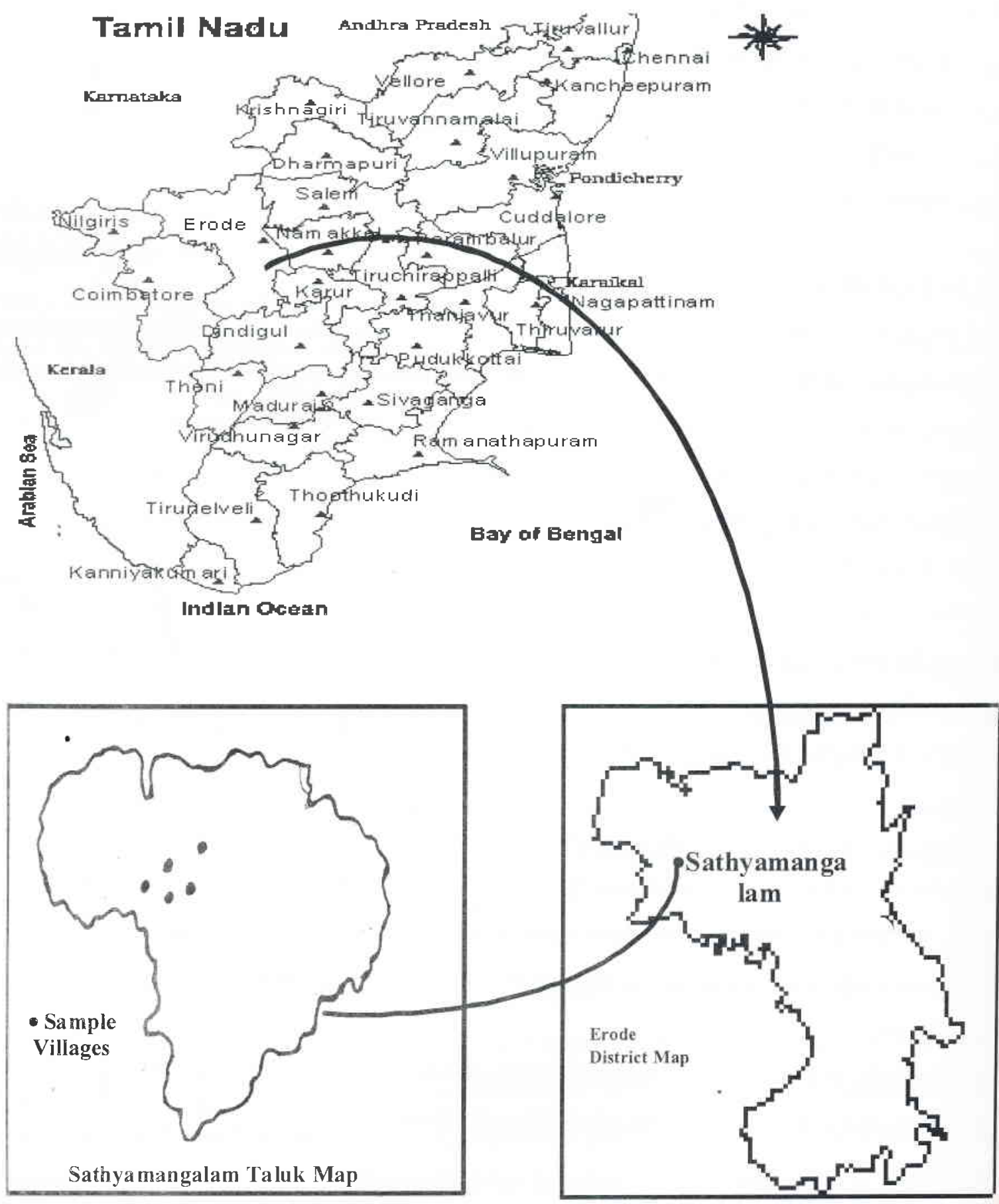




\section{RESULTS AND DISCUSSION}

The results and discussion in respect of cultivation of Sweet sorghum are furnished below.

\section{Land Use Pattern among the Sample Farms}

The land use pattern, which are in vogue with the sample farms who are cultivating sweet sorghum are furnished in Table 1. It revealed that among the 50 sample farms, 64 per cent of the sample farms are in large farm category followed by 20 per cent in medium category. In toto, it revealed that as size of holding increases, the area allocated for sweet sorghum is also increasing in actual terms. Whereas, in percentage terms, it is not so. Because, the large farms are allocating higher land area exclusively for sugarcane, turmeric, maize and ginger. But the area allocated under sweet sorghum is twice that of medium category and five times higher when compared to small farm category. Small and medium farmers are allocating to an extent of 46.46 per cent and 62.83 per cent to their respective size of holding.

Table 1. Size of Holding among the Sample Farms

\begin{tabular}{lcccc}
\hline $\begin{array}{c}\text { Category of } \\
\text { Farms (in Ha) }\end{array}$ & $\begin{array}{c}\text { Number } \\
\text { of Farms }\end{array}$ & $\begin{array}{c}\text { Size of } \\
\text { holding } \\
\text { (in ha.) }\end{array}$ & $\begin{array}{c}\text { Area under } \\
\text { Sweet Sorghum } \\
\text { (in ha.) }\end{array}$ & $\begin{array}{c}\text { Area under } \\
\text { other crops } \\
\text { (in ha.) }\end{array}$ \\
\hline Small & 8 & 0.99 & 0.46 & 0.53 \\
$(0.41-1.01)$ & $(16.00)$ & $(100)$ & $(46.46)$ & $(53.54)$ \\
Medium & 10 & 1.91 & 1.20 & 0.71 \\
$(1.02-2.02)$ & $(20.00)$ & $(100)$ & $(62.83)$ & $(37.17)$ \\
Large & 32 & 8.02 & 2.34 & 5.68 \\
$(>2.02)$ & $(64.00)$ & $(100)$ & $(29.18)$ & $(70.82)$ \\
& 50 & 10.92 & 4.00 & 6.92 \\
Total & $(100)$ & $(100)$ & $(36.63)$ & $(63.37)$ \\
& & & & \\
\hline
\end{tabular}

(Figures in parentheses indicate percentage to total)

From this one could infer that as size of holding increases, the farmers are showing more interest on allocating their land for cultivation of sweet sorghum due to the presence of Buy Back Mechanism, which are discussed under the title of factors influencing cultivation of sweet sorghum. To know the influence of age and educational status on cultivation of sweet sorghum, the details are processed and furnished in Table 2. 
Table 2. Age and Educational Qualifications of Sample Heads

\begin{tabular}{|c|c|c|c|c|c|}
\hline \multirow{2}{*}{$\begin{array}{l}\text { Category } \\
\text { of Farms }\end{array}$} & \multirow{2}{*}{$\begin{array}{c}\text { Age of Head } \\
\text { of sample } \\
\text { farms }\end{array}$} & \multirow{2}{*}{$\begin{array}{l}\text { No. of } \\
\text { Farms }\end{array}$} & \multicolumn{3}{|c|}{ Educational Qualification } \\
\hline & & & $\begin{array}{c}\text { Middle } \\
\text { Schooling }\end{array}$ & $\begin{array}{c}\text { Hr. } \\
\text { Secondary }\end{array}$ & Collegiate \\
\hline Small & 65 & $\begin{array}{c}8 \\
(100)\end{array}$ & $\begin{array}{c}4 \\
(50.00)\end{array}$ & $\begin{array}{c}3 \\
(37.50)\end{array}$ & $\begin{array}{c}1 \\
(12.50)\end{array}$ \\
\hline Medium & 48 & $\begin{array}{c}10 \\
(100)\end{array}$ & $\begin{array}{c}3 \\
(30.00)\end{array}$ & $\begin{array}{c}4 \\
(40.00)\end{array}$ & $\begin{array}{c}3 \\
(30.00)\end{array}$ \\
\hline Large & 46 & $\begin{array}{c}32 \\
(100)\end{array}$ & $\begin{array}{c}6 \\
(18.75)\end{array}$ & $\begin{array}{c}12 \\
(37.50)\end{array}$ & $\begin{array}{c}14 \\
(43.75)\end{array}$ \\
\hline Total & & $\begin{array}{c}50 \\
(100)\end{array}$ & $\begin{array}{c}13 \\
(26.00)\end{array}$ & $\begin{array}{c}19 \\
(38.00)\end{array}$ & $\begin{array}{c}18 \\
(36.00)\end{array}$ \\
\hline
\end{tabular}

(Figures in parentheses indicate percentage to total)

It revealed that the heads of medium and large farm category are in the middle age group and they posses the educational status of higher secondary and above which are accounted to be 70 per cent to the total respondents. Whereas, large farm heads are in possession of higher secondary and above are accounted to be 81 per cent to the total farms. The heads of small farms are in the age group of 65 and around 87 per cent of them had education up to higher secondary level. The educational background coupled with their age and experience in farming had motivated them to go in for allocation of land under sweet sorghum to an cxtent of 46 per cent of their total holding.

From this, one could infer that, the knowledge background and the activation of middle age forced them to choose newer technologies like sweet sorghum to earn profit by allocating considerable area for sweet sorghum. :

\section{Water Requirement for Principal Crops}

Analyzing the information of the water requirement for different crops are drawn from secondary source and are presented here to highlight the extent of water use by the principal crops. Table 3 revealed that the interval between two irrigation was found to be 15 days and require around 8 irrigation for harvesting of Sweet Sorghum.

The water requirement for Sweet Sorghum was found to be $400 \mathrm{~mm}$. The crops like Sorghum, Ragi is in the same category of consuming $400 \mathrm{~mm}$ of water for getting robust yield. The comparison of water requirement of dry land crops like Sweet Sorghum with that of Paddy and Sugarcane revealed that Paddy and Sugarcane had respectively consumed 3 times and five times higher amount of water than the Sweet Sorghum. Among the dry land crops, Gingelly, Black grams were the crops require very less quantum of water, which was found to be $250 \mathrm{~mm}$. These were reflected in the yield of crops. On summing up, Sweet Sorghum is the crop capable of consuming less water to give higher yield of stalk for the production of Bio -Fuel. In this regard, optimum age for harvesting to obtain higher yield and Ethanol are important and are discussed in Table 4. 
Table 3. Details of Water Requirement for Different Crops in Tamil Nadu

\begin{tabular}{lccccc}
\hline Crops & $\begin{array}{l}\text { Water } \\
\text { Requirement } \\
\text { (in mm ) }\end{array}$ & $\begin{array}{l}\text { Number } \\
\text { of } \\
\text { Irrigation } \\
\text { per crop }\end{array}$ & $\begin{array}{l}\text { Interval } \\
\text { between } \\
\text { two } \\
\text { Irrigations } \\
\text { (days) }\end{array}$ & $\begin{array}{l}\text { Water } \\
\text { Required } \\
\text { per } \\
\text { irrigation } \\
\text { (in mm) }\end{array}$ & $\begin{array}{l}\text { Yield of } \\
\text { Crop ( in } \\
\text { quintals } \\
\text { per ha ) }\end{array}$ \\
\hline Paddy & 1250 & 25 & 4 & 50 & 48.67 \\
Sorghum & 400 & 8 & 15 & 50 & 15.32 \\
Sweet & $400^{*}$ & 8 & 15 & 50 & 26.60 \\
Sorghum & 400 & 8 & 7 & 50 & 17.21 \\
Ragi & 450 & 5 & 11 & 50 & 5.36 \\
Black gram & 250 & 5 & 18 & 50 & 5.26 \\
Gingelly & 250 & 40 & 8 & 50 & 1150 \\
Sugarcane & 2000 & 40 & &
\end{tabular}

(Source: Palanisamy. K. Water Technology Centre, TNAU, Coimbatore - 3)

\section{Optimum Age of Harvesting and Crushing}

The Bannari Amman Sugars Limited has conducted a trial crushing of sweet sorghum to examine the optimum age of harvesting and the economic feasibility of ethanol production. The details are furnished in Table 4.

Table 4. Details of Trial Crushing of Sweet Sorghum

\begin{tabular}{|c|c|c|c|c|c|}
\hline Particulars & I & II & III & IV & V \\
\hline Age of the crop (days) & 100 & 108 & 113 & 117 & 119 \\
\hline Area Harvested in ha. & 4.67 & 4.54 & 7.77 & 7.20 & 17.98 \\
\hline $\begin{array}{l}\text { Yield of Stalk (tones per } \\
\text { ha) }\end{array}$ & 16.40 & 20.15 & 23.12 & 26.60 & 21.50 \\
\hline $\begin{array}{l}\text { Juice Weight (in tones } \\
\text { per ton-of stalk) }\end{array}$ & 0.80 & 0.72 & 0.56 & 0.43 & 0.42 \\
\hline $\begin{array}{l}\text { Yield of Alcohol per ton } \\
\text { of stalk (liters) }\end{array}$ & 39.60 & 41.82 & 36.21 & 30.28 & 27.32 \\
\hline
\end{tabular}

Table - 4 revealed that the optimum age of harvesting of sweet sorghum in respect of yield of stalk alone is arrived at 117 days. In respect of production of alcohol alone, the optimum age of harvesting is arrived at 108 days after planting. Here, the yield of alcohol is worked out to be 41.82 litres per ton of stalk of sweet sorghum.

An interesting finding drawn from the table 4 are, as age of the crop increases, the weight of the stalk also increases up to the age of 117 days. There after, a decrease could be observed in the weight of stalks due to drying of stalks because of aging. That decrease in stalk weight could be observed during 117 days to 
119 days, which is accounted for 17.31 per cent. Hence, it is suggested to go for harvesting of stalks between 115 and 117 days, if the farmer aspiring for the yield of stalks alone.

Another interesting finding drawn from the table 4 is that, as the age of crop advances, the juice weight from a ton of stalk is also decreasing from 0.80 ton during one hundredth day of harvesting to 0.42 ton of juice weight during $119^{\text {th }}$ day of harvesting. Whereas, the yield of alcohol from a ton of a stalk is concerned, the optimum age for obtaining higher amount of alcohol (41.82 litres) is 108 days after planting. Followed by, $100^{\text {th }}$ day yielded around 40 litres of alcohol. Hence, the industry should harvest the sweet sorghum between $100^{\text {th }}$ to 108 days after planting to reap higher out turn per unit of resources invested. Since the study has attempted by Bannari Amman Sugars Limited to quantify the optimum age instantaneously, it needs a detailed study, which warrants time and money.

\section{Costs and Returns from Sweet Sorghum}

Transfer of any technology should be backed by economic inventiveness' for easy adoption by the farmers. The cost incurred for different operations are compiled and furnished as Cost 'A1', Cost ' $\mathrm{B}$ ', and Cost ' $\mathrm{C}$ '. Cost $\mathrm{A} 2$, Cost $\mathrm{B} 1$ and Cost $\mathrm{C} 1$ were not arrived due to the absence of leased-in land among the sample farms. Hence, the costs are spelt here as Cost A1, Cost B and Cost $\mathrm{C}$ that are summarized in table5.

Cost $\mathrm{A} 1$ is often referred to as Operational Cost, which incorporates all actual expenses in cash and kind incurred by the farmer in the production of sweet sorghum. It is arrived at Rs. 22656, which is accounted for 88 per cent of the total cost. Among the operational costs, usage of human labour for different cultural operations alone accounted to be 38.30 per cent to the total cost, which is arrived at Rs. 9850 per ha followed by machine labor Rs. 3572 (13.89 per cent). The cost on Seed accounted to be very minimum and it is arrived at Rs. 227 ( 0.88 per cent to the total cost).

The yield of any crop depends on the level of fertilizer application. Here, organic and inorganic fertilizers application consumed Rs. 5654. Both are accounted for 22 per cent to the total cost. Among the operational cost, higher human labour usage is noticed which calls for efficiency in labor so as to minimize the cost. 
Table 5. Cost and Returns from Sweet Sorghum $(\mathrm{N}=50)$

\section{Particulars}

\begin{tabular}{lrr}
\hline Seeds & 226.87 & \\
Human Labour & 9850.78 & 38.38 \\
Machine Labour & 3572.41 & 13.89 \\
Inorganic Fertilizers & 3088.74 & 12.01 \\
Organic Manures & 2564.68 & 9.97 \\
Insacticide & 566.20 & 2.20 \\
Weediside & 572.10 & 2.22 \\
Depreciation on Farm Implements and & 155.00 & \\
Machineries & & 0.60 \\
Interest on Working Capital @ $10 \%$ & \\
per annum & 2059.68 & 8.01 \\
Cost A1 & $\mathbf{2 2 6 5 6 . 4 5}$ & 88.08 \\
Rental Value of Own Land & 1650.00 & 6.41 \\
Interest on Fixed Capital @ 10\% per & 165.00 & 0.64 \\
annum & $\mathbf{2 4 4 7 1 . 4 5}$ & 95.14 \\
Cost B & 1250.00 & 4.86 \\
Imputed Value of Family Labour & $\mathbf{2 5 7 2 1 . 4 5}$ & 100.00 \\
Cost C & 22.45 & \\
Yield in Tn per Ha (Stalk) & 3.71 & \\
Yield in Tn per Ha (Grains) & $\mathbf{5 1 0 2 5 . 0 0}$ & \\
Gross Retum & 25303.55 \\
Net Returns & $1: 1.98$ & \\
Input out put ratio & & \\
\hline
\end{tabular}

Amount

(Rs/ha)

\begin{abstract}
Cost B is here described as Cost Al plus imputed value of family labor, which is arrived at 24472, which is accounted for 95 per cent of the total cost. Cost $\mathrm{C}$ is the total cost, described here as Cost B plus imputed value of family labor and the total cost is arrived at Rs. 25721 (100 per cent).
\end{abstract}

With regard to the yield of the main product (stalk), it is arrived at 22.45 tonnes per ha and the yield of grains (by product) accounted to be 3.71 tonnes per ha. Based on the tie up entered with the Bannari Amman Sugars Limited, the stalks were taken by them for production of Ethanol. The gross return is arived at 51025 per ha and the Output - Input Ratio worked out to be 1.98 revealed that, for the investment of every rupee in sweet sorghum, it earns a gross income of Rs. 1.98 with a net return of 98 paise. It is a considerable return and hence the aspirants can come forward to raise the crop to earn higher income by managing their dry land s available with them. 


\section{Cost of Production of Ethanol}

Ethanol is a renewable source of energy, which can be produced from sweet sorghum and molasses. Since sweet sorghum is mostly used for extraction of ethanol, the cost of production of ethanol (per litre) was arrived at and compared with the one drawn from the molasses to know the cost effectiveness.

Cost of production per litre of ethanol from sweet sorghum is Rs. 13.11 and the same from molasses is arrived at Rs. 10.90. The difference in cost is mainly due to the involvement of cost on raw material procurement, which is accounted for 79.41 per cent in respect of sweet sorghum and 73.85 per cent in respect of molasses. The higher percentage in raw material is mainly due to the presence of buy back mechanism in vogue with the farmers and the industry. Here, sweet sorghum is the main product whereas; molasses is a by-product of sugarcane, which consumes lesser cost. The ethanol from sweet sorghum seems to be advantageous on the lines of no cost for pollution control measures. Hence, considering the demand for ethanol large-scale cultivation of sweet sorghum may be practiced to meet the deficiency in Bio-diesel production.

Table 6. Cost of Production of Ethanol from Sugarcane and Sweet-Sorghum in India (20032004)

\begin{tabular}{|c|c|c|}
\hline Particulars & $\begin{array}{l}\text { Sweet-Sorghum } \\
\text { (Rs./Litres) }\end{array}$ & $\begin{array}{c}\text { Sugarcane Molasses } \\
\text { (Rs./Litres) }\end{array}$ \\
\hline & 0.50 & 0.25 \\
\hline Manpower & $(3.81)$ & $(2.29)$ \\
\hline & 1.00 & 1.00 \\
\hline Steam & $(7.63)$ & $(9.17)$ \\
\hline Elentricity & 1.00 & 1.00 \\
\hline Electricity & $(7.63)$ & $(9.17)$ \\
\hline Yeasit & 0.10 & 0.10 \\
\hline Yeast & $(0.76)$ & $(0.92)$ \\
\hline Management/Administration & 0.10 & 0.25 \\
\hline Mranagentent/Aummistration & $(0.76)$ & $(2.29)$ \\
\hline Pollution Control Measures & 0.00 & $\begin{array}{r}0.25 \\
(2.29)\end{array}$ \\
\hline Raw Material & $\begin{array}{r}10.41 \\
(79.41)\end{array}$ & $\begin{array}{r}8.05 \\
(73.85)\end{array}$ \\
\hline Total & $\begin{array}{l}13.11 \\
(100)\end{array}$ & $\begin{array}{l}10.90 \\
(100)\end{array}$ \\
\hline
\end{tabular}

Source : Annual Report 2003-2004

Govt. of India.(GOI)

(Figures in parentheses indicate percentage to total) 


\section{Factors Influencing Cultivation of Sweet Sorghum}

The factors, which are influencing cultivation of sweet sorghum, are presented in Table 7.

The prime factors that could influence the farmers were presented before them for their ranking and prioritization. The factors thrown among them are suitability to the soil, profitability, and buy back mechanism, drought resistant and pest resistant. Among the five factors, 90 per cent of the sample farmers reported that drought resistance is the prime factor forced them to choose. Followed by buy back mechanism and the profitability shared 80 and 70 per cent and ranked as second and third factors in going for sweet sorghum. The study concluded that the above three are the prime factors that could influence their decisions on cultivating sweet sorghum.

The other factors like suitability to the soil and pest resistance were considered to be the least and are scored as fourth and fifth factors. However, all of them felt that the transfer of technology and the hybrid varieties in sweet sorghum are lacking so as to get higher yield.

Table 7. Factors Influencing Cultivation of Sweet Sorghum

\begin{tabular}{lcc}
\hline \multicolumn{1}{c}{ Particulars } & No of Response & Percentage \\
\hline Profitable & 35 & 70 \\
Suitable to the soil & 30 & 60 \\
Assured market & 40 & 80 \\
Pest resistance & 26 & 52 \\
Drought resistance & 45 & 90 \\
\hline
\end{tabular}

$(\mathrm{N}=50)$

\section{CONCLUSION AND POLICY IMPLICATIONS}

Increasing awareness on sweet sorghum by highlighting the importance of its profitability and drought resistance through Government institutions. High yielding varieties are to be standardized and the quality seeds should be made available to the farmers. New agro techniques are to be standardized for the production of sweet sorghum. The Research and Development fund need to be mobilized to a greater extent to assess the importance, utility and scope of this crop.

The Government policy should encourage its cultivation by way of giving incentives and subsidies to the farmers. To promote the crop, among the farmers and the industry, needed subsidy parameters are to be discussed and the same should be provided for creating the tieup. Further strong. 


\section{REFERENCES}

Annual Report (2003-2004,) Department of Agricultural Research and Education, Ministry of Agriculture, Government of India.

Dayakar Rao, C.V.Ratnavatho, P.K. Biswas, K.Karthikeyan and N.Seetharama (2004) "Sweet sorghuma potential ingredient for bio fuel production" Employment news 16-22, p2.

Directorate of Economics and Statistics (DES)," "Studies on the Economics of Farm Management in Coimbatore District, Tamil Nadu, Combined report for the year 1970-71 to 1972-73, p.241. Government of India, Ministry of Agriculture and Irrigation, p.241.

Government of India, (2004) "Report of Commission for Agricultural Costs and Prices" (Department of Agriculture and Cooperation, New Delhi), p37.

Palanisamy, K., and P. Chandrasekaran, (2011) "Irrigation Management in Tamil Nadu" (Tamil Nadu Agricultural University, Coimbatore)p.27 